\title{
Serum PTH reference values in an adult Brazilian population: implications for the diagnosis of hyperparathyroidism
}

\author{
Pedro Weslley Rosario', Maria Regina Calsolari ${ }^{1}$
}

1 Santa Casa de Belo Horizonte, Belo Horizonte, MG, Brasil

\author{
Correspondence to: \\ Pedro Weslley Rosario \\ Instituto de Ensino e Pesquisa da \\ Santa Casa de Belo Horizonte \\ Rua Domingos Vieira, 590, \\ Santa Efigênia \\ 30150-240 - Belo Horizonte, \\ MG, Brasil \\ pedrowsrosario@gmail.com \\ Received on July/23/2018 \\ Accepted on Jan/16/2019 \\ DOI: 10.20945/2359-39970000000117
}

\begin{abstract}
Objective: To define serum parathyroid hormone (PTH) reference values in carefully selected subjects following the recommended pre-analytical guidelines. Subjects and methods: First, 676 adults who would be submitted to thyroidectomy were evaluated. Patients using interfering medications or with malabsorption syndrome, hypomagnesemia, hyper- or hypophosphatemia, hypo- or hypercalcemia, 25 -hydroxyvitamin $D<30 \mathrm{ng} / \mathrm{dL}$, estimated glomerular filtration rate $<60 \mathrm{~mL} / \mathrm{min} / 1.73 \mathrm{~m}^{2}$, urinary calcium/creatinine ratio $\geq 0.25$, thyroid dysfunction, parathyroid adenoma detected during surgery were excluded. The sample consisted of 312 subjects. Results: The median, minimum, maximum, and $2.5^{\text {th }}$ and $97.5^{\text {th }}$ percentiles of the PTH values obtained were $30,7.2,78,10.1$, and $52 \mathrm{pg} / \mathrm{mL}$, respectively. Thus, the reference range was 10 to $52 \mathrm{pg} / \mathrm{mL}$. PTH $>65 \mathrm{pg} / \mathrm{mL}$, the upper limit of normal according to the manufacturer of the kit, was observed in only one subject $(0.3 \%)$. Considering the upper limit proposed by the kit's manufacturer, 1/6 hypercalcemic patients and 4/8 normocalcemic patients with PHPT had normal PTH. Using the upper limit established in this study, only one normocalcemic patient had normal PTH. Thus, the sensitivity of PTH in detecting asymptomatic primary hyperparathyroidism (PHPT) using the values recommended by the kit and established in this study was $64 \%$ and $93 \%$, respectively (50\% versus $87.5 \%$ for normocalcemic PHPT). Conclusion: The upper reference limit of PTH obtained for a rigorously selected sample was $20 \%$ lower than that provided by the assay, which increased its sensitivity in detecting PHPT. Arch Endocrinol Metab. 2019;63(2):182-5
\end{abstract}

Keywords

Normal PTH; primary hyperparathyroidism; normocalcemic; secondary hyperparathyroidism; diagnosis

\section{INTRODUCTION}

$\mathrm{T}$ he measurement of parathyroid hormone (PTH) is necessary for the diagnosis of hyperparathyroidism. In the presence of hypercalcemia, reduced PTH is expected and normal concentrations are sufficient for the diagnosis of primary hyperparathyroidism (PHPT) (1). In this situation, overestimated limits of normal PTH are unlikely to compromise the diagnosis. A more serious consequence exists in normocalcemic subjects in whom an overestimated upper limit of PTH may mask the diagnosis of normocalcemic PHPT or secondary hyperparathyroidism (SHPT).

The minimum requirements for the definition of PTH reference values is that (i) a reasonable number of apparently healthy subjects are evaluated, that these subjects are (ii) normocalcemic, (iii) have vitamin D sufficiency, (iv) do not have moderate or severe chronic kidney disease, and (v) do not use medications known to interfere with the concentrations of this hormone. A recent review shows that few studies have met all of these criteria so far (2). Even among these few studies, many defined vitamin D sufficiency as concentrations $>20 \mathrm{ng} / \mathrm{dL}(2)$. Although this definition is widely accepted, specifically to establish normal PTH values, the cut-off value of $30 \mathrm{ng} / \mathrm{dL}$ seems to be more adequate since PTH elevation can occur at vitamin $\mathrm{D}$ concentrations between 20 and $30 \mathrm{ng} / \mathrm{dL}$ (2). Furthermore, other factors that can elevate PTH in apparently healthy subjects, both recognized as a cause of SHPT and included in the differential diagnosis of normocalcemic PHPT such as hypercalciuria and conditions of malabsorption ( 1 ), were not excluded in the previous studies. In addition to the selection criteria of the subjects, guidelines on blood collection (time and need for fasting) and processing must be followed for the measurement of PTH (2). 
As we have seen, studies establishing serum PTH reference values in carefully selected subjects following the recommended pre-analytical guidelines remain desired goals. This was the objective of the present prospective study which used an assay commonly employed for the measurement of PTH.

\section{SUBJECTS AND METHODS}

\section{Study design}

The study was prospective and was approved by the local Research Ethics Committee (3).

\section{Patients}

First, 676 adults (age $\geq 18$ years) with nodular thyroid disease whowould besubmitted tobilateral thyroidectomy (3) were evaluated. The subjects were submitted to the measurement of calcium (total and ionized), magnesium, phosphorus, 25-hydroxyvitamin $\mathrm{D}$, creatinine, TSH, $\mathrm{PTH}$, and urinary calcium and creatinine. The following patients were excluded: patients using diuretics, lithium, bisphosphonates, denosumab, recombinant PTH, corticosteroids and calcium or vitamin D supplements, and patients with primary aldosteronism [investigated in the recommended situations (4)], known malabsorption syndrome, hypomagnesemia, hyper- or hypophosphatemia, hypo- or hypercalcemia, 25-hydroxyvitamin $\mathrm{D}<30 \mathrm{ng} / \mathrm{dL}$, estimated glomerular filtration rate $(\mathrm{eGFR})<60 \mathrm{~mL} / \mathrm{min} / 1.73 \mathrm{~m}^{2}$, urinary calcium/creatinine ratio $\geq 0.25$, or thyroid dysfunction. The remaining patients also underwent measurement of tissue anti-transglutaminase $\operatorname{IgA}$ antibodies and those with a positive result were excluded. Using these criteria, 356 participants were excluded.

\section{Parathyroidectomy}

Trained surgeons performed the surgery of all patients included in the study. The four parathyroid glands were fully explored and grossly abnormal parathyroid glands, i.e., enlarged, were removed. Eight patients had parathyroid adenoma detected during surgery $(5,6)$ and were also excluded. Thus, the final sample consisted of 312 subjects (Table 1 ).

\section{Methods}

Total calcium [corrected for low albumin $(<4 \mathrm{mg} / \mathrm{dL})$ using the formula: $(4-$ albumin) x $0.8+\mathrm{Ca}$ ] (reference range: 8.4 to $10.4 \mathrm{mg} / \mathrm{dL}$ ) and urinary calcium were
Table 1. Characteristics of the subjects studied

\begin{tabular}{ll}
\hline Number of patients studied & 312 \\
Sex & Female: 232 \\
& Male: 80 \\
& 18 to 70 (median: 48$)$ \\
& $<60$ years: 242 \\
Age (years) & $>-60$ years: 70 \\
& Premenopausal: 130 \\
Menopause status & Postmenopausal: 102 \\
BMl $\left(\mathrm{kg} / \mathrm{m}^{2}\right)$ & 18 to 33 (median: 25$)$ \\
\hline
\end{tabular}

BMl: body mass index.

measured by a colorimetric method. Ionized calcium (reference range: 1.12 to $1.32 \mathrm{mmol} / \mathrm{l}$ ) was measured with a selective electrode and automatic correction for $\mathrm{pH}$ variation. Serum PTH was measured with a chemiluminescent assay (Immulite 2000, Diagnostic Products Corporation, Los Angeles, CA), with reference values of $12-65 \mathrm{pg} / \mathrm{mL}$. A chemiluminescence assay was used to measure 25-hydroxyvitamin D. The eGFR was calculated using the Modification of Diet in Renal Disease Study equation. Tissue anti-transglutaminase IgA antibodies were measured by enzyme immunoassay. All measurements were obtained in the morning after fasting for approximately $10 \mathrm{~h}$, and the samples were processed and analyzed immediately after collection.

\section{Statistical analysis}

As reported in previous studies (7-19), the PTH values did not follow a normal distribution. Thus, the normality range was defined as corresponding to $95 \%$ of the results and the $2.5^{\text {th }}$ and $97.5^{\text {th }}$ percentiles as corresponding to the lower and upper limit, respectively (7-19). PTH levels were compared between men and women (preand postmenopausal) and between subjects $<60$ and $>$ 60 years (2) using the Student t-test and Kruskal-Wallis test. The two-tailed Pearson correlation coefficient test was used to analyze the correlation of age and BMI with PTH values.

\section{RESULTS}

The median, minimum, maximum, and $2.5^{\text {th }}$ and $97.5^{\text {th }}$ percentiles of the PTH values obtained were $30,7.2,78$, 10.1 , and $52 \mathrm{pg} / \mathrm{mL}$, respectively. Thus, the reference range was 10 to $52 \mathrm{pg} / \mathrm{mL}$. PTH $>65 \mathrm{pg} / \mathrm{mL}$, the upper limit of normal according to the manufacturer of the kit, was observed in only one subject $(0.3 \%)$. 
No significant difference in PTH values was observed between men and women (pre- and postmenopausal) (Table 2). There was also no statistically significant difference in the results between subjects $<60$ versus $>60$ years (Table 2), although concentrations were higher in the latter. Finally, no correlation was found between PTH values and age $(\mathrm{p}=0.18)$ or $\mathrm{BMI}$ $(\mathrm{p}=0.78)$.

To analyze the impact of a new reference range of PTH on the diagnosis of asymptomatic PHPT, we reviewed the serum PTH levels of patients diagnosed with this condition among the 676 patients initially evaluated in this study: 6 had hypercalcemic PHPT (3) and 8 had normocalcemic PHPT $(5,6)$. Considering the limit proposed by the manufacturer of the kit, $1 / 6$ hypercalcemic patients and $4 / 8$ normocalcemic patients had normal PTH. Using the upper limit established in this study, only one normocalcemic patient had normal PTH. Thus, the sensitivity of elevated PTH in detecting asymptomatic PHPT using the values recommended by the kit and established in this study was $64 \%$ and $93 \%$, respectively ( $50 \%$ versus $87.5 \%$ for normocalcemic PHPT).

Table 2. Comparison of the serum PTH values

\begin{tabular}{lcc}
\hline & $\begin{array}{c}\text { Serum PTH } \\
(\mathbf{p g} / \mathbf{m L}) \text { [range } \\
(\mathbf{m e d i a n})]\end{array}$ & p-value \\
\hline Women $(n=232)$ & $7.2-76(29.4)$ & 0.9 \\
Men $(n=80)$ & $7.4-78(30.6)$ & \\
Age $<60$ years $(n=242)$ & $7.2-65(27)$ & 0.2 \\
Age $>-60$ years $(n=70)$ & $8.5-78(33)$ & \\
Premenopausal women $(n=130)$ & $7.2-68(28.2)$ & 0.3 \\
Postmenopausal women $(n=102)$ & $8-78(32.8)$ & \\
BMl $<25^{*} \mathrm{~kg} / \mathrm{m}^{2}(n=156)$ & $8.5-78(31.2)$ & 0.7 \\
BMl $>25^{*} \mathrm{~kg} / \mathrm{m}^{2}(n=156)$ & $7.8-72(28.5)$ & \\
\hline
\end{tabular}

BMl: body mass index.

* Median.

\section{DISCUSSION}

We will first highlight some characteristics of the study. A reasonable number of subjects were evaluated. Rigorous selection was performed, following not only the traditionally required criteria [normocalcemia (in this study, total and ionized calcium); vitamin D sufficiency (defined as concentrations > $30 \mathrm{ng} / \mathrm{dL}$ ); absence of chronic kidney disease, and no use of interfering drugs
(2)], but also excluding other factors that can alter PTH in apparently healthy individuals (e.g., hypercalciuria, conditions of malabsorption, hyperphosphatemia, hypomagnesemia), which were not considered in previous studies $(2,18,19)$. In addition to the selection criteria of the subjects, for the measurement of PTH, the guidelines on blood collection and processing were followed (2). The assay chosen is commonly used for the measurement of PTH in Brazil. Finally, it is possible that the inadvertent inclusion of subjects with asymptomatic and normocalcemic PHPT overestimates normal PTH concentrations. However, in the present study, all subjects were submitted to surgical exploration of the parathyroid glands, which were apparently normal.

We found an upper limit that was $20 \%$ lower than that provided by the manufacturer of the kit ( 52 $\mathrm{pg} / \mathrm{mL}$ instead of $65 \mathrm{pg} / \mathrm{mL}$ ). As previously seen, an overestimated upper limit may mask the diagnosis of SHPT and especially of normocalcemic PHPT. In fact, $3 / 8$ cases of normocalcemic PHPT from our series $(5,6)$ would have their diagnosis masked if the values proposed by the kit and not the upper limit obtained in this study were used.

A significant influence of sex, age or BMI on PTH concentrations was not observed in the present study. Any observed differences in PTH concentrations might be due to differences in vitamin $\mathrm{D}$ concentrations, eGFR, comorbidities and medication use, which was not the case in the present study in which the subgroups were uniform in terms of the selection criteria (vitamin $\mathrm{D}>30 \mathrm{ng} / \mathrm{dL}$, eGFR > $60 \mathrm{~mL} /$ $\mathrm{min} / 1.73 \mathrm{~m}^{2}$, no comorbidities or use of interfering medications). However, we recognize that any difference may not have been detected because of the size of the subgroups (18).

In conclusion, the upper limit of the serum PTH reference range obtained for a sample of rigorously selected subjects was $20 \%$ lower than that provided by the assay, which increased the sensitivity of PTH in detecting normocalcemic PHPT.

Funding: this work was supported by the National Council for Scientific and Technological Development (CNPq).

Compliance with Ethical Standards: the study was approved by the Research Ethics Committee of our institution.

Disclosure: no potential conflict of interest relevant to this article was reported. 


\section{REFERENCES}

1. Eastell R, Brandi ML, Costa AG, D'Amour P, Shoback DM, Thakker RV. Diagnosis of asymptomatic primary hyperparathyroidism: proceedings of the Fourth International Workshop. J Clin Endocrinol Metab. 2014;99:3570-9.

2. Souberbielle JC, Brazier F, Piketty ML, Cormier C, Minisola S, Cavalier $\mathrm{E}$. How the reference values for serum parathyroid hormone concentration are (or should be) established? J Endocrinol Invest. 2017:40:241-56.

3. Rosário PW, Mourão GF, Calsolari MR. Screening for Hyperparathyroidism by Measurement of Calcium in Patients Undergoing Thyroid Surgery: A Prospective Study. Horm Metab Res. 2016;48:673-6.

4. Funder JW, Carey RM, Mantero F, Murad MH, Reincke M, Shibata $\mathrm{H}$, et al. The Management of Primary Aldosteronism: Case Detection, Diagnosis, and Treatment: An Endocrine Society Clinical Practice Guideline. J Clin Endocrinol Metab. 2016;101(5):1889-916.

5. Rosário PW. Primary Hyperparathyroidism with Normal Calcium and PTH. World J Surg. 2017;41:1649-50.

6. Rosario PW, Calsolari MR, Oliveira LFF, Oliveira PHL, Silva TH. Normocalcemic primary hyperparathyroidism in adults without a history of nephrolithiasis or fractures: a prospective Brazilian study. Arq Endocrinol Metab. 2018;62(Suppl 4):S144.

7. Souberbielle JC, Cormier C, Kindermans C, Gao P, CantorT, Forette $\mathrm{F}$, et al. Vitamin $\mathrm{D}$ status and redefining serum parathyroid hormone reference range. J Clin Endocrinol Metab. 2011;86:3086-90.

8. Glendenning P, Vasikaran S. Comment on: Vitamin D status and redefining serum $\mathrm{PTH}$ reference range in the elderly. J Clin Endocrinol Metab. 2002;97:946-7.

9. Souberbielle JC, Fayol V, Sault C, Lawson-Body E, Kahan A, Cormier A. Assay-specific decision limits for two new automated parathyroid hormone and 25-hydroxyvitamin D assays. Clin Chem. 2005;51:395-400.

10. Aloia J, Feuerman M, Yeh J. Reference range for serum parathyroid hormone. Endocr Pract. 2006;12:137-44.
11. La'ulu S, Roberts W. Performance characteristics of six intact parathyroid hormone assays. Am J Clin Pathol. 2010;134:930-8.

12. Rejnmark L, Vestergaard P, Heickendorff L, Mosekilde L. Determinants of plasma PTH and their implication for defining a reference interval. Clin Endocrinol. 2011;74:37-43.

13. Fillée C, KellerT, Mourad M, BrikmanT, Ketelslegers JM. Impact of vitamin D-related serum PTH reference values on the diagnosis of mild primary hyperparathyroidism, using bivariate calcium/ PTH reference regions. Clin Endocrinol. 2012;76:785-9.

14. Deckers $M$, de Jongh R, Lips P, Penninx B, Milaschi $Y$, Smit J, et al. Prevalence of vitamin D deficiency and consequences for PTH reference values. Clin Chim Acta. 2013;426:41-5.

15. Touvier M, Deschasaux M, Montourcy M, Sutton A, Charnuax N, Kess-Guyot E, et al. Interpretation of plasma PTH concentrations according to $250 \mathrm{HD}$ status, gender, age, weight status, and calcium intake: importance of the reference values. J Clin Endocrinol Metab. 2014;99:1196-203.

16. Djennane M, Lebbah S, Roux C, Djoudi H, Cavalier E, Souberbielle JC. Vitamin D status of schoolchildren in Northern Algeria, seasonal variations and determinants of vitamin $D$ deficiency. Osteoporos Int. 2014;25:1493-502.

17. Li M, Lv F, Zhang Z, Deng W, Li Y, Deng Z, et al. Establishment of a normal reference value of parathyroid hormone in a large healthy Chinese population and evaluation of its relation to bone turnover and bone mineral density. Osteoporos Int. 2016;27: 1907-16.

18. Farrell CL, Nguyen L, Carter AC. Parathyroid hormone: Data mining for age-related reference intervals in adults. Clin Endocrinol (Oxf). 2018;88:311-7.

19. Cavalier E, Salsé M, Dupuy AM, Bargnoux AS, Watar F, Souberbielle JC, et al. Establishment of reference values in a healthy population and interpretation of serum PTH concentrations in hemodialyzed patients according to the KDIGO Guidelines using the Lumipulse $^{\circledR} \mathrm{G}$ whole PTH (3rd generation) assay. Clin Biochem. 2018;54:119-22. 